\title{
Estratégia, Estrutura e Competências Gerenciais: estudo de uma operadora de plano de saúde, modalidade autogestão
}

Djair Picchiai ${ }^{1}$

\section{Resumo}

Este estudo trata da análise de uma operadora de plano de saúde, modalidade autogestão. Foram analisadas sua estratégia, estrutura organizacional e competências gerenciais, a luz dos conceitos encontrados na literatura. Descrevese a estrutura, as diretrizes de atuação e satisfação dos clientes através da análise de documentos e entrevistas com seus principais gestores. Verifica-se como são entendidos e utilizados esses conceitos na relação da operadora com os prestadores de serviços e beneficiários. A literatura aponta para a coerência, o alinhamento $e$ a consistência entre os conceitos de estratégia, estrutura e competências gerenciais, como forma de aumento de competitividade e desenvolvimento de competências organizacionais. Os indicadores de desempenho e o mapa estratégico aparecem como instrumentos desta avaliação.

Palavras-chave: Estratégia. Estrutura. Competência gerencial. Competências essenciais.

\section{Introdução}

Trata-se de um estudo de caso de uma operadora de plano de saúde, modalidade autogestão. Faz-se aqui uma análise de sua estratégia, estrutura organizacional e competências gerenciais, a luz das categorias conceituais, encontradas na literatura. Será descrito o funcionamento da operada através da análise de documentos, leis, estatuto e regimento interno e entrevistas com seus principais gestores, além de visitas e conversas informais (observação direta)

As operadoras de planos de saúde, modalidade autogestão, são organizações de pequeno e médio porte em termos de recursos humanos, mas

${ }^{1}$ Professor da Escola de Administração de Empresas da Fundação Getúlio Vargas (EAESP-FGV) e do Programa de Mestrado Profissional em Administração de Micro e Pequena Empresa da FACCAMP. Endereço: Faculdade Campo Limpo Paulista. Rua Guatemala, n. 167 Jardim América, CEP01321-230 - Campo Limpo Paulista, SP. E-mail: djair.pichiai@fgv.br. Artigo recebido em: 01/09/2008. Aceito em: 10/08/2009. Membro do Corpo Editorial Científico responsável pelo processo editorial: Martinho Isnard Ribeiro de Almeida. 
grandes quando se fala na contratação de serviços e movimentação de recursos. São empresas que utilizam muito conhecimento e informação, são organizações profissionais, como classifica Mintzberg (1995). São empresas que buscam, com sua estratégia, a sobrevivência em um mercado competitivo e em processo de concentração. Suas estruturas procuram dar respostas às necessidades de sua operação e são condicionados pela estratégia adotada. A geração e desenvolvimento de competências organizacionais e gerenciais são elementos de sustentação destas na competição. As pessoas e suas competências são elementos centrais nessa relação.

Estudos organizacionais de casos empíricos, utilizando categorias conceituais, ajudam no desenvolvimento do conhecimento aplicado. Buscou-se contribuir com exemplo o que vem sendo analisado na literatura de estudos de administração.

As micros, pequenas e médias empresas são campos importantes de estudos organizacionais, pois são responsáveis pelo aumento de competitividade e fortalecimento de nossa economia. Este estudo de caso pretende contribuir para aplicação concreta dos conceitos de estratégia, estrutura e competência e suas interrelações.

Será feita uma breve avaliação da literatura, que é muito extensa, e o entendimento definido sobre esses conceitos, para tanto será utilizada literatura específica sobre o assunto. Verificou-se no estudo da operadora como tais conceitos são aplicados na sua atuação junto ao mercado, ou seja, como são utilizados e as possíveis relações entre eles.

A literatura aponta para a coerência, o alinhamento e a consistência entre os conceitos de estratégia, estrutura e competência (FLEURY, 2004), quando aplicados como forma de aumento de competitividade, por parte da organização.

\subsection{Caracterização da Operadora}

É uma Fundação que presta serviços a funcionários de uma grande empresa estatal da área de saneamento. Essa Fundação atua em dois grandes ramos de atividades: previdência e assistência à saúde. Analisa-se, neste artigo, apenas o setor de assistência à saúde.

A estrutura da área da saúde é composta de uma diretoria de saúde e três gerências. Há um diretor de benefícios ao qual a diretoria de saúde é 
subordinada. A empresa possui 100 funcionários e dá cobertura a 52.000 vidas. É atendida por 9.000 empresas prestadoras de serviços de saúde.

As patrocinadoras são: a Companhia de Saneamento Básico do Estado de São Paulo (Sabesp), a Fundação Sabesp de Seguridade Social (Sabesprev), bem como outras pessoas jurídicas admitidas como tal, que venham a assinar o Convênio de Adesão previsto na legislação em vigor. Estas são responsáveis pela supervisão e fiscalização das atividades da Fundação, devendo encaminhar o resultado das suas análises ao órgão regulador e fiscalizador.

A Sabesprev administra: planos previdenciários (planos de suplementação e plano de reforço), planos médicos (Sabesprev saúde, plano alternativo e intermédica), odontológicos (plano convencional e plano integral); empréstimos (empréstimo pessoal) e seguros (seguro de vida em grupo).

São membros da Fundação: patrocinadoras, participantes (ativos e assistidos) e os dependentes.

A Sabesprev tem como visão ser a melhor opção em serviços de previdência e saúde em um mercado expandido, excedendo as expectativas e necessidades dos clientes, proporcionando alta satisfação com os produtos/ serviços oferecidos e rentabilidade adequada, em um ambiente organizacional dinâmico e harmonioso. Sua missão é contribuir, de forma responsável, para que seus clientes tenham uma qualidade de vida digna e saudável. Os valores são: orientar as ações de forma profissional, ética e transparente; manter relacionamento respeitoso e pró-ativo com os clientes; manter a integridade e sigilo das informações dos clientes; praticar gestão participativa; valorizar o capital humano interno na busca de excelência e manter sinergia, confiança e comprometimento nas relações com os patrocinadores, conselhos, parceiros e entidades representativas de forma a possibilitar benefícios recíprocos.

A diretoria executiva da Sabesprev e seus colaboradores estão comprometidos em garantir a efetividade do sistema de gestão de qualidade, através da: melhoria contínua de seus processos e produtos; capacitação e aperfeiçoamento dos colaboradores; cumprimento dos requisitos legais e estatuários; geração de indicadores de performance voltado para resultados e tendências elaborados a partir de metas acordadas; buscar soluções mais indicadas aos seus clientes; satisfação das necessidades e expectativas dos clientes com rentabilidade consistente; manter relações harmoniosas com os parceiros, visando benefícios recíprocos. 
No foco da gestão administrativa destaca-se: investimento em treinamento, sistema de controle de acesso, incremento dos processos de compras médicas e aproveitamento interno de recursos humanos.

\section{Objetivos}

O objetivo geral desse artigo é verificar o nível de alinhamento, de consistência e de coerência entre estratégia, estrutura e competências gerenciais. O objetivo específico é verificar o entendimento dos conceitos de estratégia, estrutura e competências gerenciais, na prática, pelos principais gestores.

\section{Metodologia}

A metodologia se constitui nas análises de documentos, leis, estatuto e regimento interno e a estrutura da instituição. Foram realizados, também, entrevistas com os principais gestores da instituição através da aplicação de um questionário com 40 perguntas. Foram feitas várias visitas, com conversas informais e observação direta do dia a dia da operadora. É um estudo de caso. Sua natureza de análise é qualitativa e exploratória.

\section{Conceitos}

Estratégia é uma palavra oriunda do vocabulário grego "strategos". Significa o desempenho de uma posição de comando. É também considerada arte do general - habilidades psicológicas e comportamentais com a qual o general exercia sua função (ou posição) (MOTTA, 1990). Na língua inglesa, a estratégia envolve algo fora da visão do inimigo.

A estratégia é uma atividade que tem relação com o meio ambiente da organização, como ela lida com o mercado e a sociedade. É uma atividade voltada para fora da organização. A estratégia é um caminho para cumprir a missão e visão da organização; reforçar seus valores e crenças e atingir objetivos institucionais. 
A estrutura organizacional deve estar atrelada à estratégia da organização. Essa estrutura está condicionada pela estratégia a ser adotada (CHANDLER, 1962). Por sua vez, a estrutura também influencia a estratégia, no momento da execução desta.

As competências gerenciais são determinadas pelo modelo organizacional adotado e os respectivos papéis exercidos pelos gestores.

\subsection{Estratégia}

É a formulação da visão, da missão e dos objetivos da organização, bem como o plano de ação para alcançá-los, considerando as forças e fraquezas internas e os impactos das forças do ambiente e da competição. Os valores e crenças dos fundadores, líderes, gestores e membros da comunidade de interesses são determinantes no estabelecimento da visão, missão $e$ objetivos. Direciona a empresa e dá consistência nas suas decisões. Resulta de um processo de tomada de decisão. As suas decisões são de natureza qualitativa e devem ter coerência entre si.

A formulação da estratégia é, essencialmente, um processo de reflexão, sistematizado e formalizado, ou implícito.

A implementação é a estratégia em ação, a intenção convertendo-se em resultado, enfim, a capacidade de executar a estratégia. A formulação deve ser integrada com a implantação da estratégia. "A capacidade de executar a estratégia é mais importante do que a qualidade da estratégia [...] $70 \%$ dos fracassos decorrem de problemas de má execução da estratégia" (KAPLAN; NORTON, 2004, p. 6).

O conceito de arquitetura estratégica é composto dos seguintes elementos, a saber: definir claramente a estratégia de negócio; construir um core business como um componente estratégico; criar um mapa estratégico, identificando indicadores tangíveis e intangíveis; identificar os produtos no mapa estratégico; alinhar a estrutura com os "produtos"; desenhar sistemas de mensuração (scorecard); implementar o gerenciamento por indicadores; revisar continuamente as mensurações, comparando-as ao mapa estratégico.

A estratégia também pode ser entendida como um padrão consistente de escolhas. Um padrão de decisões na empresa que determina e revela seus objetivos e propósitos; um posicionamento de ataque e defesa em relação aos concorrentes em busca de vantagens competitivas no mercado; um pa- 
drão global de decisões e ações que posicionam a organização no seu ambiente e têm o objetivo de fazê-la atingir seus objetivos a longo prazo; um padrão integrativo de decisões e ações, orientado por objetivos, que equaciona os recursos e capacitações organizacionais com as oportunidades e ameaças em seu ambiente externo.

Na metodologia de Kaplan e Norton (2004), há a mensuração da estratégia através de indicadores com a seguinte estrutura:

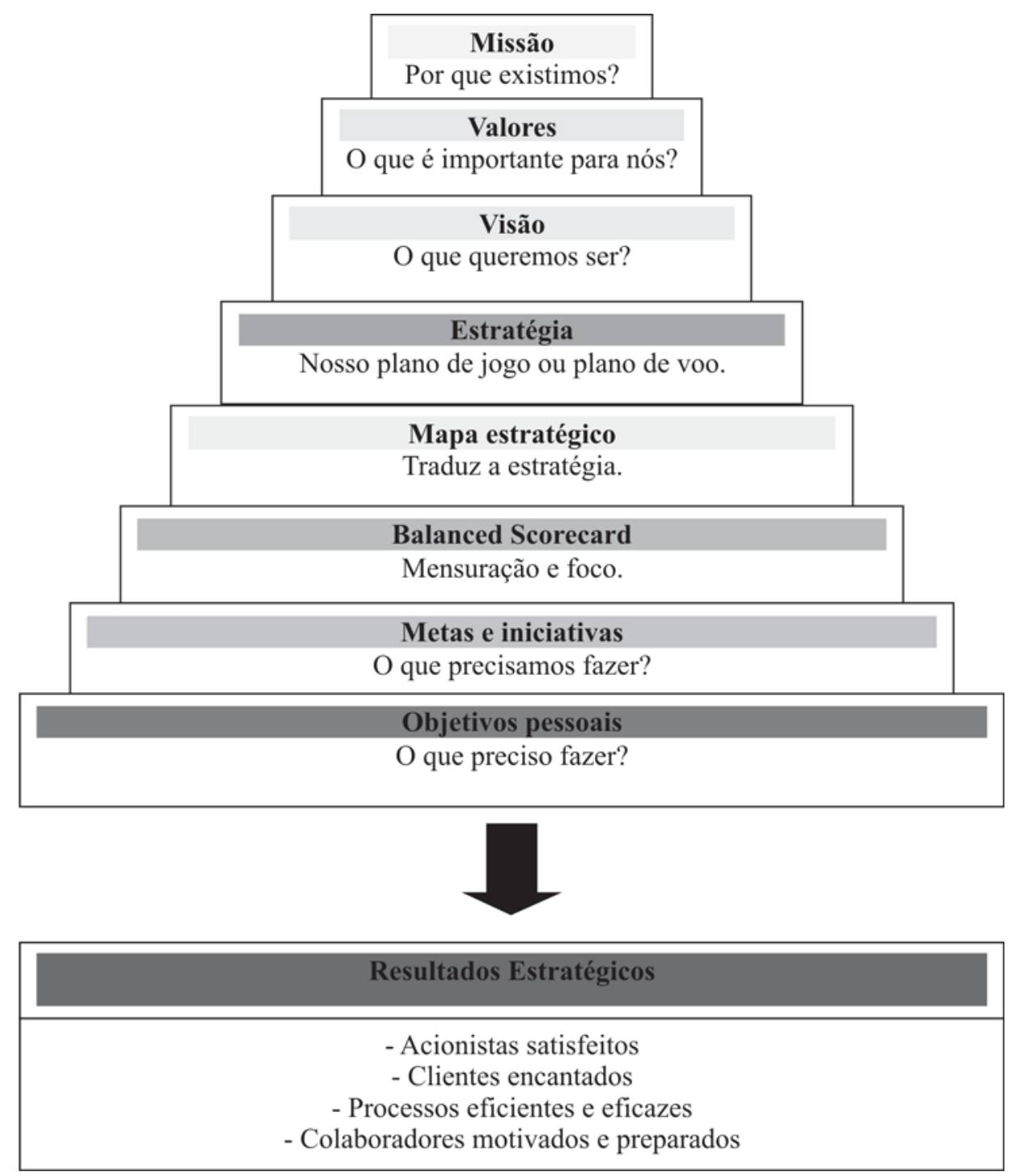

Figura 1: Alinhamento e Mensuração.

Fonte: Kaplan e Norton (2004). 


\section{I.I Planejamento Estratégico}

O planejamento estratégico é algo mais complexo do que simplesmente um objetivo a atingir.

É visto como um processo, um plano de ação e um projeto que envolve visão, formulação, implantação e avaliação dos resultados. Pode-se entendêlo através dos níveis da Figura 2.

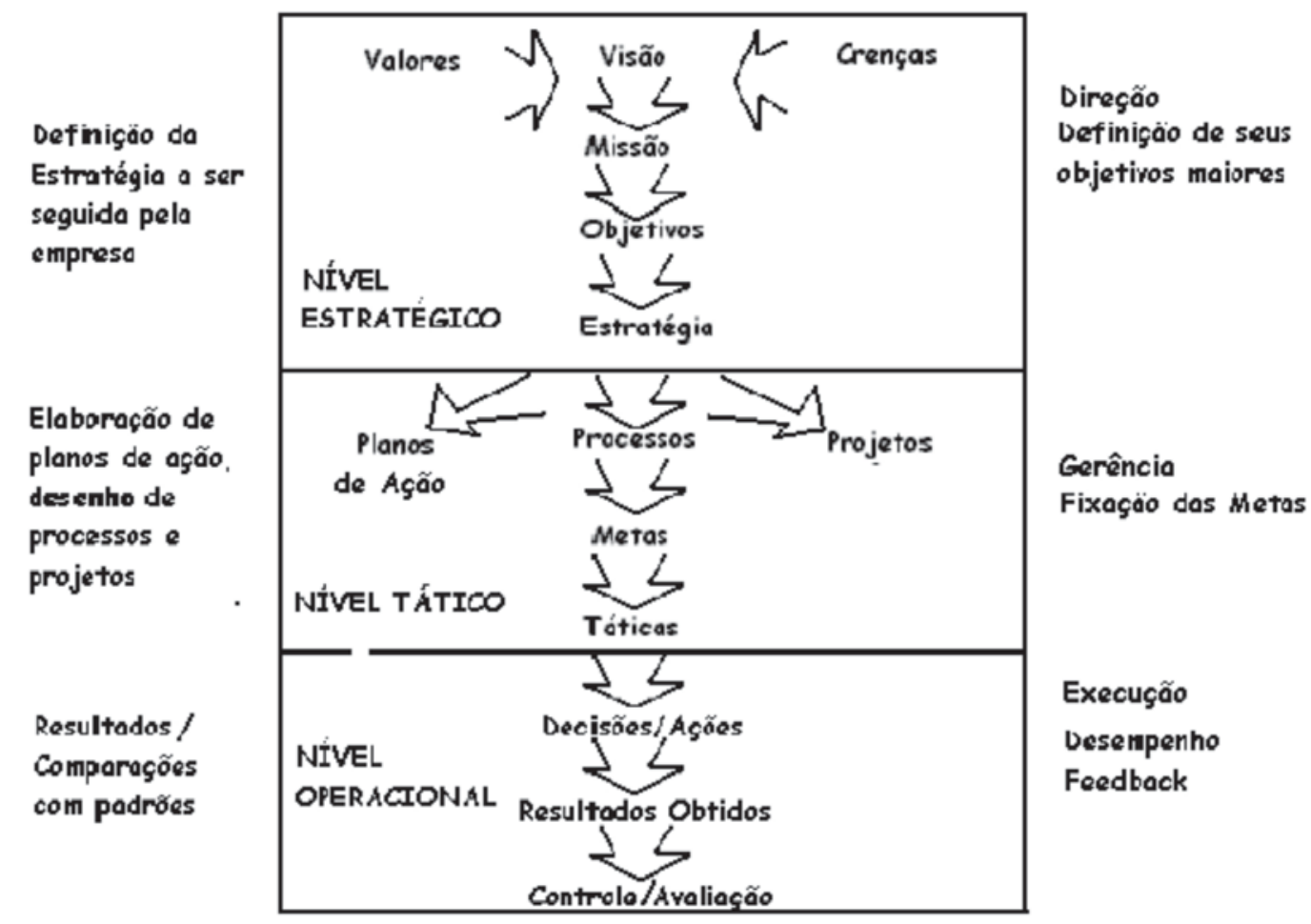

Figura 2: A importância da coerência entre os três níveis, o alinhamento e o sentido de unidade na operadora.

Fonte: Elaborado pelo autor.

As organizações com clareza estratégica demonstram foco, definem processos de alocação de recursos usados de maneira eficaz e com visão. A unidade estratégica envolve funcionários e clientes nos fins (objetivo) e nos meios (processos) do trabalho realizado pela organização. Tem-se aqui a coerência e consistência das ações estratégicas.

Mintzberg (2000) resume as dez escolas de pensamento em administração estratégica, a saber: design: estratégia como um processo de concepção 
(Selznik); planejamento: estratégia como um processo formal e sistemático (Ansoff); posicionamento: estratégia como um processo analítico (Porter); empreendedora: estratégia como um processo visionário (Schumpter); cognitiva: estratégia como um processo mental (Simon); aprendizado: estratégia como um processo emergente (Prahalad); poder: estratégia como um processo de negociação (Allison); cultural: estratégia como um processo coletivo (Norman); ambiental: estratégia como um processo reativo (Freedman); configuração: estratégia como um processo de transformação (Chandler).

A análise SWOT da organização é a avaliação global de suas: forças (strenghs): variáveis internas e controláveis que propiciam uma condição favorável para a empresa em relação ao seu ambiente; fraquezas (weaknesses): variáveis internas e controláveis que produzem uma situação desfavorável para a empresa em relação ao seu ambiente; oportunidades (opportunities): variáveis externas e não controláveis que podem criar condições favoráveis para a empresa, desde que a mesma tenha condições e/ou interesse de usufruí-las; ameaças (threats): variáveis externas e não controláveis.

Há a premissa de que uma empresa só pode controlar seu próprio destino (futuro) se aprender a controlar o destino de seu setor. Segundo os autores Hamel e Prahalad (1995), a transformação organizacional é um desafio secundário. O principal desafio é ser o autor da transformação do setor.

No livro Estratégia em Ação (KAPLAN; NORTON, 2004), as adeptas bem-sucedidas seguiam cinco princípios gerenciais para tornar-se "organização orientada para a estratégia", a saber: traduzir a estratégia em termos operacionais; alinhar a organização à estratégia; transformar a estratégia em tarefas de todos; converter a estratégia em processo contínuo; mobilizar a mudança por meio da liderança executiva.

A organização orientada para a estratégia propõe resultados notáveis = Descrição da estratégia + Mensuração da estratégia + Gestão da estratégia (KAPLAN, 2001).

Um dos requisitos-chave da governança corporativa é a transparência da estratégia da organização, bem como o do seu acompanhamento. Os conselhos de administração têm neste sentido requisitado a explicitação da estratégia para a sua aprovação e acompanhamento.

A estratégia de uma organização descreve como ela pretende criar valor para os acionistas, clientes e cidadãos. Se os ativos intangíveis da organização representam mais de $75 \%$ de seu valor, a formulação e a execução da 
estratégia deve tratar explicitamente da mobilização e alinhamento dos ativos intangíveis (KAPLAN; NORTON, 2004).

Os sistemas de mensuração chamam a atenção de todos, no entanto, para que exerçam o maior impacto possível, esses sistemas devem concentrar-se na estratégia da organização, como ela espera criar valor sustentável no futuro. Assim, ao projetar os Balanced Scorecards, a organização deve medir os poucos parâmetros críticos que representam sua estratégia para a criação de valor a longo prazo (KAPLAN; NORTON, 2004).

Estratégia não é um processo gerencial isolado; é uma das etapas de um processo contínuo lógico que movimenta toda a organização desde a declaração de missão de alto nível até o trabalho executado pelos empregados da linha de frente e de suporte (Figura 2).

A teoria de recursos da firma, ou recourse based view of the firme (RBV), utiliza elementos que ressaltam a complexidade subjetiva e a dinâmica dos processos internos da firma, definindo que os produtos finais sendo produzidos pela empresa, em um dado momento, representam apenas uma das múltiplas possibilidades pelas quais a empresa poderia estar utilizando seus recursos, um incidente no desenvolvimento de suas potencialidades básicas (PENROSE, 1959).

O modelo de cinco forças de Porter, para análise das forças competitivas, pode ser representado pela Figura 3.

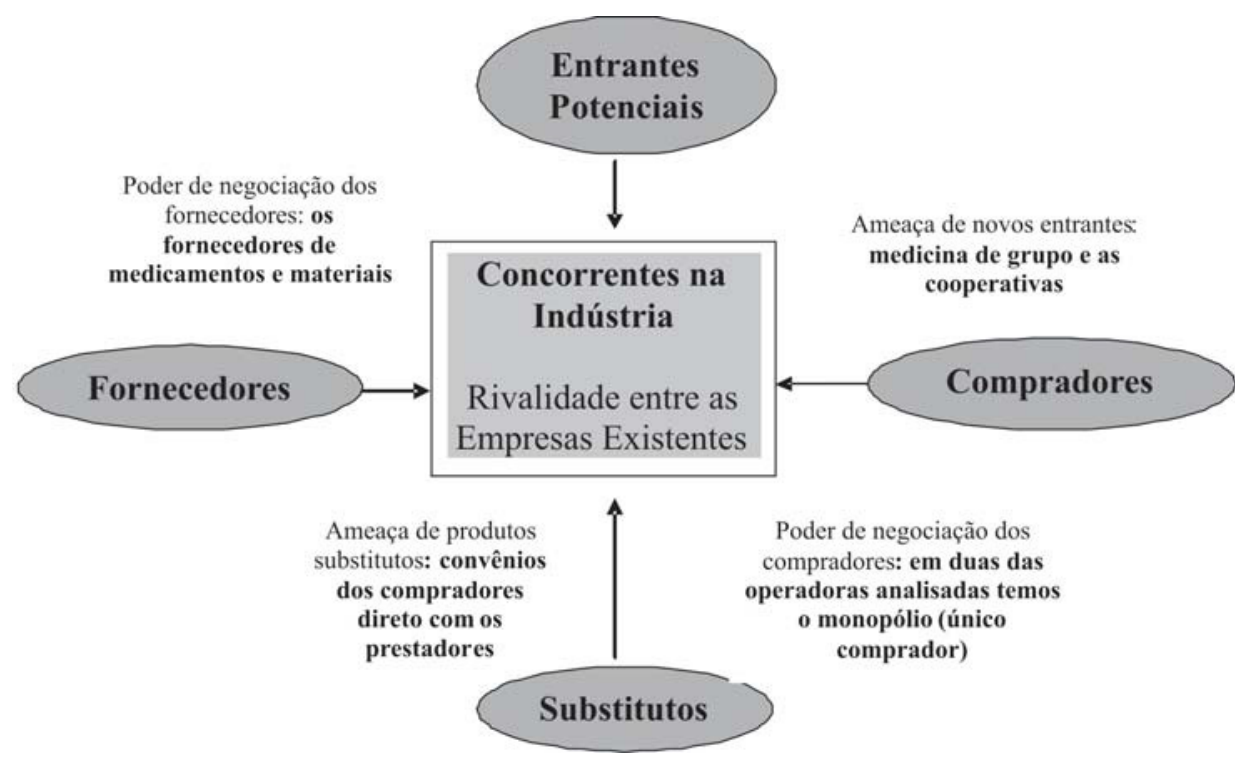

Figura 3: As cinco forças competitivas.

Fonte: Porter (1980). 
Penrose (1959) descreve recursos como algo que representa uma força ou fraqueza de uma dada empresa, sejam eles tangíveis ou não. Distingue o uso da simples possessão de um recurso, pois o que diferencia um serviço ou produto é a alocação concatenada e com determinada intensidade das potencialidades da firma.

A diferença de performance entre as organizações pode ser entendida seguindo a RBV, pois esta mobiliza seus recursos de modo a se tornarem mais competitivos.

A RBV considera as competências, as capacidades e habilidades de forma genérica e os recursos internos como a base do conhecimento organizacional, sendo elas responsáveis por diferenciar uma organização das demais.

\subsection{Estrutura}

A estrutura de uma organização é a soma total das maneiras pelas quais o trabalho é dividido em tarefas distintas e como é feita a coordenação entre essas partes.

O projeto de organizações deve combinar planejamento a longo prazo, enriquecimento do trabalho e estrutura, entre muitas outras coisas. Os elementos de uma estrutura devem ser selecionados para alcançar uma congruência interna ou harmonia, bem como uma congruência básica com a situação da organização (suas dimensões e idade, seu tipo de ambiente no qual opera, o sistema técnico que utiliza e assim por diante). A esses fatores situacionais devem ser acoplados os parâmetros para delinear, formando as configurações (MINTZBERG, 1995).

A estrutura envolve duas exigências básicas: a divisão do trabalho em diferentes tarefas e a consecução da coordenação. A coordenação é composta por diversos meios, os chamados "mecanismos de coordenação", dentre os quais estão inclusos o controle e a comunicação.

Há cinco mecanismos de coordenação que abrangem as maneiras fundamentais pelas quais as organizações coordenam suas tarefas. Segundo Mintzberg (1995), eles são: ajustamento mútuo: o controle do trabalho permanece nas mãos dos operadores, com base no processo simples da comunicação informal. Normalmente é utilizado em organizações mais simples. O sucesso do empreendimento depende da habilidade dos especialistas em 
se adaptarem um com o outro no decurso de suas "rotas"; supervisão direta: ocorre quando a organização começa a se desenvolver e crescer. A responsabilidade pelo trabalho dos outros e pelo monitoramento de ações é delegada a uma pessoa, que passa a coordenar todo o esforço através de uma coordenação direta de outras pessoas; padronização dos processos de trabalho: existem três formas básicas de conseguir padronização nas organizações: as habilidades (e conhecimentos) de quem executa o trabalho, os processos de trabalho em si mesmos e as saídas desses processos de trabalho. A coordenação é obtida antes de o trabalho ser efetivado. O que caracteriza a padronização é o fato das execuções serem específicas ou programadas; padronização dos resultados: neste caso, os resultados são especificados, desde que o operador saiba como realizar a tarefa, cabe à coordenação cuidar para que determinados resultados sejam atingidos; padronização das habilidades (e conhecimentos) dos trabalhadores: é utilizada quando nem o processo de trabalho, nem seus resultados podem ser padronizados. Neste caso, as habilidades e conhecimentos são padronizados, a fim de ter um treinamento específico para a execução de determinado trabalho.

As organizações não dependem de um único mecanismo de coordenação, podendo adotar um misto de todas as cinco formas de coordenação. Normalmente supervisão direta e ajustamento mútuo são exigidos.

As organizações são estruturadas, a fim de apreender e dirigir sistemas de fluxos e determinar os interrelacionamentos das diferentes partes. As cinco partes que a compõem, segundo Mintzberg (1995), são: núcleo operacional: composto pelos operadores, ou seja, as pessoas que executam o trabalho básico de fabricar produtos ou prestar serviços. Nas organizações mais simples, os operadores são grandemente autossuficientes, coordenando-se por meio do ajustamento mútuo; cúpula estratégica: refere-se a uma forma de supervisão direta, utilizada à medida que a organização cresce e a divisão de trabalho requer uma supervisão em tempo integral; linha intermediária: criada a partir da necessidade em ter mais cargos de chefia dentro da organização, conforme esta se expande, há uma hierarquia de autoridade entre o Núcleo Operacional e a Cúpula Estratégica; tecnoestrutura: formada por analistas, ou seja, pessoas situadas fora da linha de autoridade da organização, com o propósito de coordenar o trabalho, visando o crescimento da organização; assessoria de apoio: refere-se à parte da organização cujas unidades prestam assessoria de natureza diferente às demais unidades, não efetuando a padronização. 
A organização pode operar sob diversas formas: fluxo da autoridade formal: refere-se ao fluxo do poder formal hierarquia abaixo. Apesar desse modelo de organograma já estar sendo considerado inadequado, ele representa um retrato da divisão de trabalho e exibe as posições existentes na organização, o agrupamento das mesmas em unidades e a forma como a autoridade formal opera sobre elas; fluxos regulamentados: é um modelo que dá mais ênfase à padronização do que à supervisão direta; fluxo das comunicações informais: enfatiza o ajustamento mútuo na coordenação; sistema de processo decisório ad hoc: representa uma decisão estratégica desde seu início até seu fim; sistema de constelação: neste tipo de operação, os membros pertencentes à organização se agrupam por afinidades, não estando relacionada à hierarquia dentro da mesma.

O sistema de controle de desempenho dá origem aos objetivos globais, que possibilitarão a elaboração dos planos estratégicos.

A fim de interligar as posições, a superestrutura da organização e os sistemas, foram criados os instrumentos de interligação. Esses instrumentos devem atingir a coordenação de que a organização precisa, já que qualquer forma de padronização, por si só, não permite tal coordenação.

Os instrumentos de interligação representam esquemas desenvolvidos com o intuito de estabelecer contatos (interligações) entre os indivíduos e podem ser incorporados à estrutura formal. Eles são: posições de interligação: podem ser estabelecidas formalmente. A posição não tem autoridade formal, mas por estar no cruzamento dos canais de comunicação, tende a ter considerável poder; forças-tarefa e comissões permanentes: a força-tarefa é uma comissão formada apenas para realizar uma tarefa específica, sendo dissolvida depois. A comissão permanente é um grupo interdepartamental mais estável, que se reúne regularmente para discutir assuntos de interesse comum; gerente integrador: este instrumento é criado quando há a necessidade de uma coordenação por ajustamento mútuo maior do que as outras formas de coordenação podem atender; estrutura matricial: base utilizada para agrupar todas as interdependências; instrumentos de interligação por partes da organização.

As Formas de estrutura organizacional, descritas por Mintzberg (1995), são, a saber: estrutura simples: caracterizada pela pouca elaboração. Possui pequena ou nenhuma tecnoestrutura, ou assessoria de apoio, diferenciação mínima entre as unidades e pequena hierarquia administrativa. Há pouco planejamento, treinamento e instrumentos de interligação; burocracia 
mecanizada: nela há padronização de responsabilidades, de qualificações e de canais de comunicação. Há normas de trabalho e hierarquia de autoridade devidamente definidas; burocracia profissional: nela o trabalho operacional é estável. Há mecanismos de coordenação que permitem, ao mesmo tempo, a padronização e a descentralização e a padronização de habilidades. É um tipo de configuração democrática e autônoma; forma divisionalizada: é um conjunto de entidades (divisões) quase autônomas, unidas por meio de uma central administrativa - o escritório central. Essa estrutura é amplamente utilizada no setor privado. Representa um tipo de configuração sobreposta a outras, em que cada divisão apresenta sua própria estrutura; adhocracia: é capaz de fundir indivíduos de diferentes especialidades, em equipes de projetos had hoc. É uma estrutura orgânica, com pouca formalização de comportamento e com o trabalho baseado no treinamento formal. Tem uma tendência a agrupar os especialistas em unidades funcionais, com finalidade de administração interna e possui apoio nos instrumentos de interligação para encorajar o ajustamento mútuo. É uma forma de estrutura fluída, confusa e que pode causar ambiguidade.

\subsection{Competências}

O termo competência tem origem no fim da Idade Média. Inicialmente, restrito à linguagem jurídica significava que determinada corte, tribunal ou indivíduo era "competente" para realizar um dado julgamento. Era considerada a "capacidade de apreciar e julgar certas questões ou realizar determinados atos". Foi utilizado para designar alguém capaz de pronunciar-se sobre certos assuntos (BRANDÃO; GUIMARÃES, 2001).

Pode-se definir competência como as características demonstráveis de um indivíduo que incluem conhecimentos, habilidades e comportamentos ligados diretamente com a performance. Um conjunto de capacidades humanas que justificam uma alta performance.

Para alguns autores, a maioria de origem norte-americana, competência é o conjunto de qualificações que permite à pessoa uma performance superior em um trabalho ou situação. Richard Boyatzis identificou competências gerenciais como um conjunto de características e traços que definem uma performance superior. Acredita-se que as melhores performances estão fundamentadas na inteligência e personalidade do indivíduo. Seus princi- 
pais expoentes McClelland (1973), Boyatzis (1982) e Spencer Jr. e Spencer (1993).

Parry (1996) resume o conceito de competências como um cluster de conhecimentos, skills e atitudes relacionados que afetam a maior parte de um job, que se relacionam como performance do job, que possa ser medida contra parâmetros bem aceitos, e que pode ser melhorada através de treinamento e desenvolvimento.

McClelland (1973) coloca competência como uma característica subjacente a uma pessoa relacionada a uma tarefa. Entende competência como um estoque de qualificações, que credencia a pessoa a exercer determinado trabalho. Competência como performance superior na realização de uma tarefa.

As competências pode ser entendidas como um conjunto de aprendizagem sociais e comunicacionais. Saber agir responsável, como tal reconhecido pelos outros, implica em saber como comunicar, mobilizar, integrar e transferir recursos e habilidades num contexto profissional e social determinado.

Como competência é uma característica relacionada à performance superior na realização de uma tarefa ou em determinada situação, McClelland (1993) diferencia competência de habilidade: demonstração de um talento particular na prática; aptidão: talento natural de uma pessoa, que pode vir a ser aprimorado; conhecimento: aquilo que as pessoas precisam saber para desempenhar uma tarefa. Competência é pensada como um conjunto de conhecimentos, habilidades e atitudes (isto é, o conjunto de capacidades humanas) que justificam a obtenção de uma alta performance.

O trabalho não é mais o conjunto de tarefas associadas descritivamente ao cargo, mas se torna o prolongamento direto das competências que o indivíduo mobiliza em face de uma situação profissional cada vez mais mutável e complexa.

Zarifian (2001) associa competência não a um conjunto de qualificações que credencia a pessoa a exercer determinado trabalho, mas sim as realizações da pessoa em determinado contexto, ou seja, aquilo que ela produz ou realiza. Diferencia as seguintes competências: sobre processos: conhecer o processo de trabalho; técnicas: conhecer especificamente o trabalho a ser realizado; sobre a organização: saber organizar os fluxos de trabalho; de serviço: aliar a competência técnica à pergunta "que impacto este produto ou serviço terá sobre o consumidor final?"; sociais: saber ser, inclu- 
indo atitudes que sustentam os comportamentos das pessoas. Três são os domínios dessas competências: autonomia, responsabilização e comunicação.

A competência não pode estar contida nas pré-condições da tarefa; e a pessoa precisa sempre mobilizar recursos para resolver as novas relações de trabalho. As competências são sempre contextualizadas.

Os conhecimentos e o know-how não adquirem status de competência a não ser que sejam comunicadas e utilizadas. A rede de conhecimento em que se insere o indivíduo é fundamental para que a comunicação seja eficiente e gere competência.

Zarifian (2001) enfoca três mutações no mundo do trabalho, a saber: noção de evento: aquilo que ocorre de forma imprevista, não programada. Isso significa que a competência não pode estar contida nas pré-condições de tarefa; a pessoa precisa mobilizar recursos para resolver as novas situações de trabalho; comunicação: implica conhecer o outro e a si mesmo, significa entrar em acordo sobre os objetivos organizacionais, partilhar normas sobre sua gestão; noção de serviço: cada vez mais essa noção precisa estar presente em todas as áreas e situações, não só direcionada ao cliente externo, mas também ao cliente interno. Ninguém produz uma coisa voltando-se para si mesmo, mas sim, destinando-as aos outros.

Para Le Boterf (1995), competência é definida como cruzamento de três eixos formados pelas pessoas: sua biografia (socialização), sua formação educacional e sua experiência profissional. A competência de um indivíduo não é um estado, não se reduz a um conhecimento ou know-how específico.

Competência como produto de uma combinação de recursos (LE BOTERF, 1995) e no saber mobilizar e aplicar esses recursos em que reside a riqueza profissional, ou seja, a competência. É o conjunto de aprendizagens sociais e comunicacionais, nutridas e montante, pela aprendizagem e pela formação e a jusante pelo sistema de avaliações.

Vandrell e Miranda (apud FLEURY, 2002) classificam seis tipos de competências necessárias, a saber: intelectual: processos cognitivos internos necessários para simbolizar e representar ideias, imagens, conceitos, etc. (competência analítica, criativa ou meta competência); prática: saber fazer, articular tomada de decisão e colocar em ação; interativa: capacidade de participar como membros de um grupo de referência; social: uso do consenso, no exercício de aceitação da liderança, da capacidade de ensinar e aprender com os outros; ética: discernimento entre o bem e o mal, direito à vida, a outras culturas, crenças, religiões, amor e educação; estética: capacidade 
de distinguir entre o que há de bom e de ruim, no plano de valores, entre o belo e o feio.

Para Prahalad e Hamel (1990), competência é um conjunto de habilidades e tecnologias e não uma única habilidade e tecnologias isoladas que permitem a uma empresa oferecer determinado benefício. Core Competences (Competências essenciais): capacidade de combinar, misturar e integrar recursos em produtos e serviços. Tem-se aqui o link entre estratégia e competências. Para adquirir papel-chave, as competências devem atender a três requisitos: oferecer reais benefícios aos consumidores; ser difícil de imitar; $e$ prover acesso a diferentes mercados.

Maria Tereza Leme Fleury (2002, p. 55) define competências como:

[...] é um saber agir responsável e reconhecido, que implica em mobilizar, integrar, transferir con hecimentos, recursos, habilidades que agregam valor econômico à organização e valor social ao indivíduo.

As competências são dinâmicas, pois sua alavancagem e a construção de novas competências exigem interação entre: as pessoas e equipes dentro da organização, empresas e fornecedores externos; clientes e empresa; organizações competitivas e organizações cooperativas.

As competências distintivas são os quesitos que o cliente e o mercado veem como diferenciais em uma empresa e a torna competitiva no cenário analisado. São características estratégicas e é através das quais a organização adquire vantagem competitiva e agrega valor ao cliente.

As tipologias das competências podem ser: a) competências organizacionais: são as capacidades especiais que uma organização tem no intuito de atingir seus objetivos estratégicos. São adquiridas ao longo do tempo, pela organização, através da composição de diversas competências individuais, processos internos e uma cultura organizacional. Exemplos: capacidade de inovar - Google; capacidade de integrar recursos - Embraer; agilidade, transparência e segurança - FEDEX; cordialidade, diversidade de atrações e segurança - Hopi Hari; b) competências individuais: tornam o indivíduo "único", como: flexibilidade, adaptação a novas ideias, foco no futuro, "rompe paradigmas", capacidade de transformar ideias em produtos, etc.; Saber agir, saber aprender, se engajar; Mobilizar recursos, integrar conheci- 
mentos díspares e complexos; Iniciativa, assumir riscos, ter visão estratégica, responsabilidade.

Ruas (2000) apresenta os recursos das competências e os desdobramentos possíveis deste modo: saber/conhecimento - conhecimento do ambiente: conhecer os elementos do ambiente, a fim de poder atuar de maneira adequada; conhecimentos gerais e teóricos: saber compreender e analisar as situações em que atua e tratá-las sistematicamente (método); conhecimentos operacionais: conhecer os métodos, procedimentos e normas associados a suas atividades; saber fazer (habilidades) - experiência profissional associada: saber colocar em ação os conhecimentos adequados à situação; Saber ser/agir - atributos profissionais: saber perceber e apropriar aspectos que não são explicitados nas normas, procedimentos e métodos, mas que estão presentes nas atividades profissionais. (conhecimentos tácitos); atributos pessoais: atributos que permitem agir, comprometer-se e relacionar-se de forma adequada em sua atividade.

Segundo Dutra (2004), as pessoas possuem determinado conjunto de conhecimentos habilidades e atitudes, o que não garante que a organização se beneficie deles. Para compreender o conceito de competência, é necessário incorporar a noção de entrega, ou seja, aquilo que a pessoa realmente entrega à organização.

A Figura 4 ilustra a relação entre estratégia, competências organizacionais e individuais.

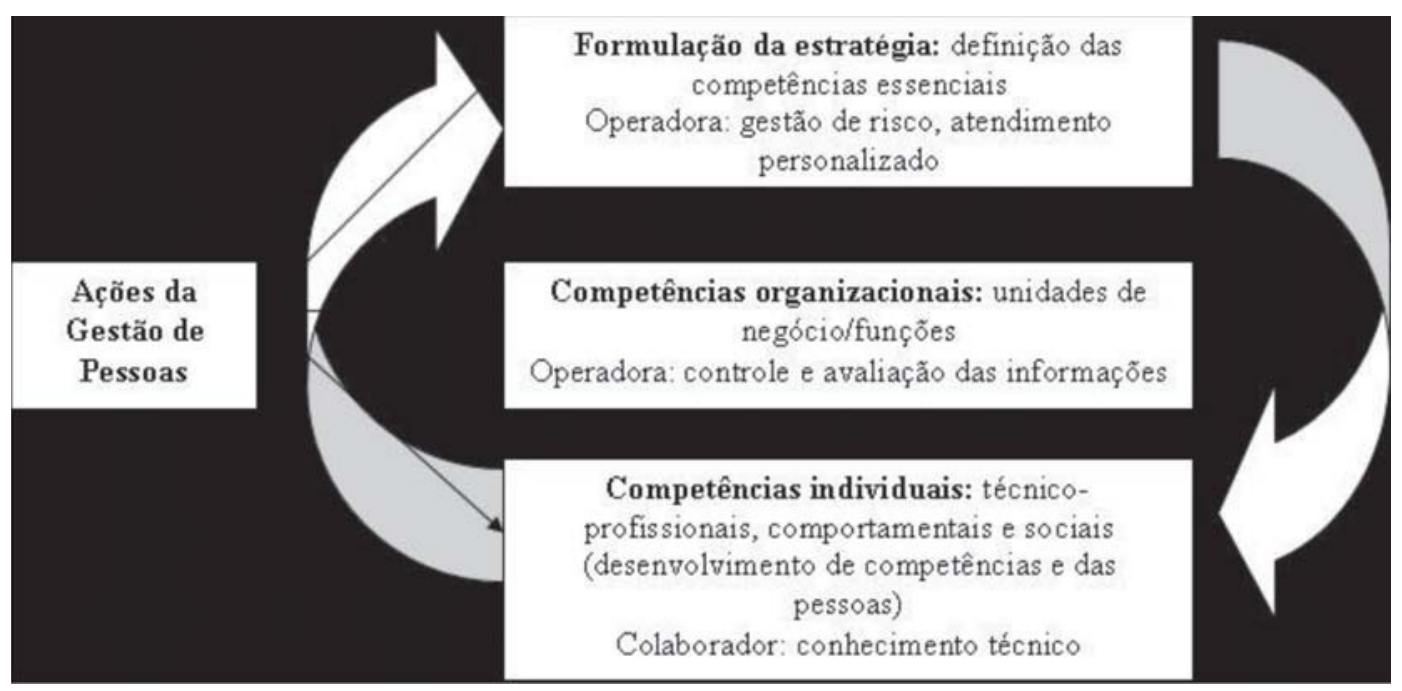

Figura 4: Estratégia, Competências Organizacionais e Individuais.

Fonte: Elaborada pelo autor. 
Exemplos (FLEURY, 2002): a Embraer, empresa criada pelos professores do ITA, possui estratégia de inovação em produtos. Seu primeiro produto foi o "Bandeirante", considerado uma inovação radical (transporte aéreo regional). A competência essencial da empresa é a inovação, desenvolvimento e gestão de projetos; além disso, a competência na integração dos serviços e dos componentes na montagem do avião, em tempo real; o McDonald's apresenta estratégia de excelência operacional, a empresa procura otimizar a relação preço/qualidade. A qualidade, a rapidez e o preço criam um sentido de confiança com relação à marca; o Laboratório Fleury, centro de medicina diagnóstica, utiliza estratégia de orientação para serviços e atende às necessidades dos clientes específicos. Além disso, oferece um serviço diferenciado de alta qualidade e confiabilidade para um segmento do mercado disposto a pagar por ele.

A Figura 5 procura representar as relações entre os conceitos de recursos, competência, aprendizagem e estratégia.

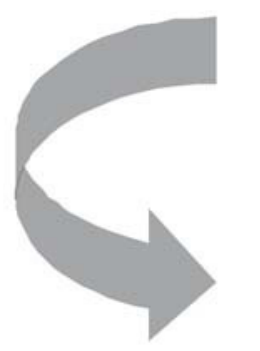

\section{Estratégia}

Aprendizagem
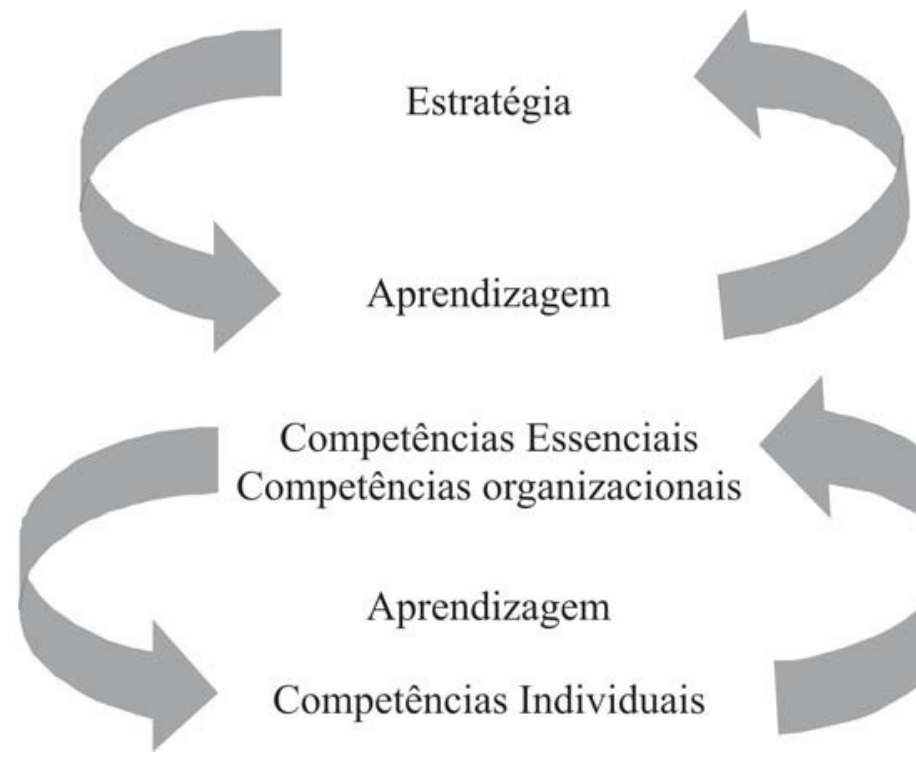

Competências Essenciais Competências organizacionais

\section{Aprendizagem}

Competências Individuais

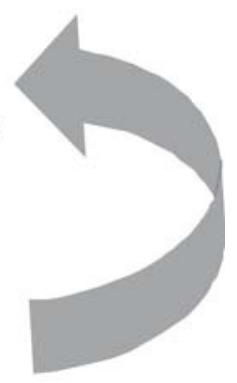

Figura 5: Competências, Aprendizagem e Estratégia.

Fonte: RAE (2004). 


\section{Análises das Informações}

A estratégia deve ser explicitada, discutida e constantemente avaliada pela empresa. Ela é uma atividade da empresa voltada para fora, portanto, depende do ambiente. Muitas vezes é hábito prender-se a uma forma de pensar e agir e não percebe-se as mudanças do ambiente e, principalmente, das necessidades do cliente. A Sabesprev foca o cliente (beneficiário) e tem na Sabesp uma parceria na sua atuação no mercado.

A modalidade autogestão de operadoras tem maior índice de satisfação de atendimento pelos usuários, pois as pesquisas divulgadas relatam isso e confirmam o posicionamento dos gestores da Sabesprev nas entrevistas, sobre o atendimento.

Entre as operadoras de planos de saúde, as de modalidade autogestão ocupam o primeiro lugar na satisfação das empresas que contratam os serviços. O nível de satisfação das organizações com seus planos de saúde é considerado "Alto" para $45 \%$ das que optam por operadoras de saúde de modalidade autogestão, superando largamente os índices referentes às seguradoras $(14 \%)$, das administradoras de planos (11\%), cooperativas médicas (15\%) e medicinas de grupo (18\%). A constatação está registrada na 26a Pesquisa de Benefícios, realizada pela consultoria Towers Perrin, em 2007, que ouviu dirigentes de 300 empresas de vários ramos de atuação. Isso confirma uma competência da Sabesprev que é o atendimento humanizado. No caso da Sabesprev, certas vantagens foram observadas nas entrevistas e análises de documentos e pesquisas com os usuários.

As principais vantagens do modelo de autogestão e sua estrutura, segundo os gestores, são: o lucro revertido em maiores benefícios para os usuários (cliente); o programa de saúde concebido de acordo com as características e necessidades da organização (parceria); a garantia de qualidade, da abrangência, da economia e a burocracia reduzida proporcionarem satisfação e consequentemente maior adesão dos beneficiários (cliente); permite interferência direta na administração do programa, ou seja, na escolha dos credenciados ou na prestação e utilização de serviços, preservando a qualidade da assistência (foco); permite a correção de problemas e a criação de novas alternativas, quando necessário (consistência); só são pagos os serviços realmente efetuados pelos profissionais e instituições de saúde (coerência); permite agregar outros tratamentos, tais como: odontológicos, psicológicos e fonoaudiológicos, bem como oferecer auxílios para medicamentos, 
órteses óticas e materiais ortopédicos, até que o programa alcance o nível de atenção à saúde e de incentivo à qualidade de vida (humanismo); custos finais inferiores aos planos de saúde equivalentes em outras modalidades do mercado (consistência); facilita ações conjuntas com o programa de saúde ocupacional (consistência); a organização é vista como promotora do bemestar físico e social de seus empregados e dependentes. Esses fatos demonstram o alinhamento com os interesses dos usuários.

$\mathrm{O}$ ambiente das operadoras é muito regulamentado. Há várias instituições reguladoras, a Agência Nacional de Saúde (ANS), a Agência Nacional de Vigilância Sanitária (ANVISA) e o Ministério da Fazenda (MF), que interferem na sua operacionalização e estratégia.

A restrição encontrada foi a necessidade de outras formas de financiamento, ou seja, outras patrocinadoras além da Sabesp. Esse é apontado como um dos fatores limitativos da estratégia.

A modalidade de autogestão é uma solução para a assistência à saúde dos beneficiários de instituições que possuem uma grande escala populacional. Nessa modalidade, a empresa e os beneficiários do plano pagam apenas pelos serviços utilizados, não existe mercantilização, nem as sucessivas renegociações contratuais e seus prejuízos decorrentes.

As competências organizacionais são importantes para discutirmos sua relação com as competências gerenciais e individuais. Inicialmente, as pessoas eram encaradas como um tipo de recurso na construção de competências. Barney (1991) classificava os recursos organizacionais em três categorias: físicos (plantas, equipamentos, ativos); humanos (gerentes, força de trabalho, treinamento) e organizacionais (imagem, cultura). A literatura mais recente considera como recursos os conhecimentos e as habilidades que a organização adquire ao longo do tempo (KING et al., 2002).

Sabe-se que as pessoas estão inseridas em todos os recursos, independente da forma como são classificadas e, consequentemente, estão na geração e sustentação das competências organizacionais.

A Sabesprev tem na utilização e no arranjo dos seus recursos a oportunidade de obter vantagens competitivas no mercado. 
Estratégia, Estrutura e Competências Gerenciais: estudo de uma operadora de plano de saúde, modalidade autogestão

\section{Considerações Finais}

A estratégia é fortemente influenciada pela regulamentação estatal (ANS). A legislação é complexa e às vezes é conflitante, o que dificulta a definição de estratégia. $\mathrm{O}$ risco e sua gestão são elementos colocados como fundamentais no estabelecimento da estratégia pelos gestores.

A estrutura é de uma burocracia profissional especializada, com forte necessidade de controle e com órgãos colegiados participando de decisões estratégicas.

O conceito de competências é entendido como conhecimento e qualificação dos funcionários. Não é feita a relação do conceito de competências com performance e resultados. Os papéis gerenciais de uma forma geral são entendidos e definidos, mas com relação às suas competências gerencias respectivas, encontramos um pouco de dificuldade conceitual e de percepção por parte dos gestores.

O mercado é visto como restritivo, os custos de assistência são crescentes, $e$ as empresas têm um aumento nos seus custos de manutenção dos planos.

As operadoras dos planos de autogestão encontram na terceirização dos quadros de funcionários das patrocinadoras e no processo de privatização das estatais ameaças à sua continuidade, isso é claramente identificado pelos gestores da Sabesprev

A lei dos planos de 1998 e a criação da ANS, em 2000, definiram papéis do público e privado na relação de prestação de serviços. São esses os grandes marcos regulatórios no entender dos gestores da Sabesprev.

A amplitude e a complexidade interferem na fiscalização operacional dos planos de autogestão, por parte da ANS. Não se pode engessar essa relação com excessos de regulamentação $e$ torná-la muitas vezes burocrática, sem a geração de valor para a sociedade. A fiscalização interfere no desenho organizacional da operadora, sua estrutura fica mais onerosa.

O entendimento da gestão corporativa e seus controles ocorrem de forma a obedecerem a princípios legais, metas e objetivos institucionais. Foram encontrados indicadores estratégicos institucionalizados e alguns estudos na explicação do momento atual da operadora. O mapa estratégico não foi encontrado como uma ferramenta de avaliação e controle.

O olhar para o concorrente e o tentar fazer melhor não são boas estratégias. O olhar para fora deve ser amplo e profundo, descartando as ideias 
preconcebidas e procurando o novo. A empresa deve estar atenta para a inovação (criatividade, motivação, recursos e conhecimento). A inovação é um processo permanente que deve estar presente em todas as áreas da empresa. Essa inovação tem que fazer parte de seu DNA, os gestores têm clareza disso, mas as ações neste sentido praticadas pela operadora não reforçam tal intenção.

As operadoras de planos de autogestão, fundações, são instituições que pela sua natureza e origem têm um componente político-profissional muito forte. A Sabesprev não foge a essas características. Foram fundadas para atender "os benefícios" de um universo de profissionais de uma empresa. As características encontradas no perfil das competências dos gestores foram as competências de negociadores de conflitos e de atendimento aos beneficiários, segundo modelo de (2003).

A cultura organizacional traz, no seu interior, a cultura das estatais do nosso modelo de desenvolvimento econômico e social das décadas de 60, 70 e 80 .

Os planos odontológicos continuam a ser a estrela (plano em expansão), dado o seu custo baixo para os beneficiários. Vêm crescendo bem acima da média do setor, quase cinco vezes mais. Embora os dados finais de 2007 ainda não tenham sido divulgados pela Agência Nacional de Saúde Suplementar, tudo indica que o segmento (plano odontológico) deve chegar perto da média anual de crescimento de $18,5 \%$ no seu número de associados, obtida entre 2001 e 2006. O número é alto, mas ainda, se comparado ao segmento médico que tem crescido a taxas de $3,6 \%$ ao ano em média no mesmo período, não é suficiente.

A escolha estratégica da Sabesprev deve ser feita a partir do mapeamento de seus recursos, das suas competências gerenciais e do meio ambiente. O relacionamento com os stakeholders, as empresas, os empregados, os fornecedores, os prestadores e o Estado é fundamental. Os documentos analisados e as entrevistas com os gestores apontam para essa direção.

Foi encontrada certa dificuldade na identificação das competências organizacionais da operadora. Sabe-se que as competências organizacionais são formadas a partir das competências individuais e gerenciais na utilização dos recursos organizacionais.

Enfim, a aprendizagem intrínseca a esse processo cria novas competências individuais em círculo virtuoso, é um processo dinâmico. 


\title{
Strategy, Structure end Responsibilities Gerenciais: study of an operator of health plan, "modalidade autogestão"
}

\begin{abstract}
The study concerns the analysis of an operator of health plan, self mode. We review your strategy, organizational structure and managerial skills, the light of the concepts found in the literature. We describe the structure, guidelines, performance and customer satisfaction through the analysis of documents and interviews with its key managers. We check they are understood and used these concepts in respect of the carrier with service providers and beneficiaries. The literature points to the coherence, consistency and alignment between the concepts of strategy, structure and managerial skills as a way to increase the competitiveness and development of organizational competencies. The performance indicators and strategic map appear as instruments of this evaluation.
\end{abstract}

Key-words: Strategy. Structure. Managerial competence. Essential competence.

\section{Referências}

BARNEY, J. B. Firm resources and sustained competitive advantage. Journal of Management, v. 17, n. 1, p. 99-120, 1991.

BOYATZIS, R. E.; MCCLELLAND, D. C. Leadership motive pattern and longterm success in management. Journal of Applied Psychology, Washington, v.67, iss. 6, p. 737-44, Dec. 1982.

BRANDÃO, H. P.; GUIMARÃES, T. A. Gestão de Competências e Gestão de desempenho humano: tecnologias distintas ou instrumentos de um mesmo constructo? Revista de Administração de Empresas. São Paulo, v. 41, n. 1, p. 8-15, jan./mar. 2001.

CHANDLER, A. Strategy and Structure: the history of the american industrial enterprise. Cambridge: Mass MIT Press, 1962. 
Djair Picchiai

DUTRA, Joel S. et al. Gestão por competência: um modelo avançado para o gerenciamento de pessoas. São Paulo: Editora Gente, 2001.

Competências: conceitos e instrumentos para a gestão de pessoas na empresa moderna. São Paulo: Editora Atlas S.A, 2004.

FERNANDES, Bruno H. R. et al. Construindo o diálogo entre competência, recursos humanos e desempenho Organizacional. RAE, v. 46. n. 4, out./dez. 2006.

FERREIRA, Aurélio. B. de H. Novo Dicionário da Língua Portuguesa. Rio de Janeiro: Nova Fronteira, 1975.

FLEURY, M. T. L et al. As pessoas na organização. São Paulo. Editora Gente, 2002.

FLEURY, Afonso; FLEURY, Maria T. Alinhando estratégia e competências. RAE, v. 44, n. 1, janeiro/março, São Paulo, 2004.

KAPLAN, Robert. S; NORTON, David P. A estratégia em Ação: balanced scorecard. Rio de Janeiro: Editora Campus. 2001.

Mapas estratégicos: convertendo ativos intangíveis em resultados tangíveis. Rio de Janeiro: Editora Campus. 2004.

Balanced Scorecard. 22. ed. Rio de Janeiro: Editora Campus, 2006

KING, A.W; FOWLER, S. W; ZEITHAML, C. P. Competências organizacionais e vantagem: o desafio da gerência intermediária. RAE - Revista de administração de empresas, v. 42, n. 1, p. 36-49. São Paulo: janeiro/março, 2002.

LE BOTERF, G. De la competénce - Essai sur un attacteur étrange. Les Èditions d'Organizations. Quatrème tirage, Paris, 1995.

MCCLELLAND, D. C. Testing for competence rather than intelligence.

American Psychologist, Washington, 1973.

MINTZBERG, Henry. Criando Organizações Eficazes: estruturas em cinco configurações. São Paulo: Editora Atlas, 1995. 
Estratégia, Estrutura e Competências Gerenciais: estudo de uma operadora de plano de saúde, modalidade autogestão

MINTZBERG, Henry; AHLSTRAND, B; LAMPEL, J. Safári de Estratégias: um roteiro pela selva do planejamento estratégico. Porto Alegre: Bookman, 2000.

MOTTA, Paulo R. Gestão contemporânea: a ciência e a arte de ser dirigente. Rio de Janeiro: Campus.1990.

PARRY, S. B. The quest for competencies. Training, July, 1996.

PENROSE, E. The Theory of Growth of the Firm. Londom: Basil Blackwell. 1959.

Planos de Benefícios no Brasil: 26 ${ }^{\mathrm{a}}$ Pesquisa - 2007. Towers Perrin. Disponível em: http://www.towersperrin.com/tp/getwebcachedoc?webc=BRA/2008/ 200808/Towers_Perrin_Pesquisa_Beneficios_2007_Final_LCK.pdf. Acesso em: 25 abr. 2008.

PORTER. Michael. Estratégia competitiva: técnicas para análise de indústrias e da concorrência. Rio de Janeiro: Editora Campus, 1980.

PORTER. Michael; TEISBERG. Elizabeth O. Repensando a Saúde: estratégias para melhorar a qualidade e reduzir os custos. São Paulo: Bookman, 2006.

PRAHALAD, C. K; HAMEL G. Competindo pelo futuro: estratégias inovadoras para obter o controle de seu setor e criar os mercados de amanhã. Rio de Janeiro: Campus. 1995.

The core competence of the corporation. Harvard Business Review, v. 68, no 3, may/jun. 1990.

QUINN, Robert E. et al. Competências gerenciais: princípios e aplicações. Rio de Janeiro: Editora Campus, 2003.

REBOUÇAS, Djalma. Estruturas organizacionais: conceitos, metodologias e práticas. 4. ed. São Paulo: Atlas, 1984.

RUAS, R. A problemática do desenvolvimento de competências e a contribuição da aprendizagem organizacional. In: FLEURY, M. T; OLIVEIRA JR.; M. M. Gestão estratégica do conhecimento: integrando aprendizagem, conhecimento e competências. São Paulo: Atlas, 2000.

SPENCER, L. M.; SPENCER, S. M. Competence a work: models for superior performance. New York: John Wiley \& Sons, 1993. 